\title{
On High-Temperature Materials: A Case on Creep and Oxidation of a Fully Austenitic Heat-Resistant Superalloy Stainless Steel Sheet
}

\author{
A. Kanni Raj \\ Faculty of Mechanical Engineering, The Indian Engineering College, Tirunelveli 627116, Tamil Nadu, India \\ Correspondence should be addressed to A. Kanni Raj; akanniraj@gmail.com
}

Received 21 November 2012; Revised 8 January 2013; Accepted 22 January 2013

Academic Editor: Te-Hua Fang

Copyright (C) 2013 A. Kanni Raj. This is an open access article distributed under the Creative Commons Attribution License, which permits unrestricted use, distribution, and reproduction in any medium, provided the original work is properly cited.

\begin{abstract}
The creep behavior of AISI 310S stainless steel taken from SAIL's Salem stainless steel plant has been investigated by constant load tensile creep test at the temperatures of 973,1023 , and $1073 \mathrm{~K}$ and loads of $66.6,74.8,86.6$, and $94.8 \mathrm{MPa}$. It exhibits steady-state creep behavior in most test conditions. The double logarithm plot of rupture life and applied stress yielded straight lines at all the three test temperatures indicating that power-law creep due to dislocation climb is the operating mechanism of creep deformation. Linear relationship was obtained for plots of logarithm of rupture life against inverse temperature obeying Arrhenius type of temperature dependence with activation energy of $340 \mathrm{~kJ} / \mathrm{mol}$. The stress-rupture data yielded a master curve of Larson-Miller parameter. The plot of Monkman-Grant relationship is typical indicating that rupture is controlled by growth of grain boundary cavities. The metallographic examination of crept samples revealed formation of grain boundary voids and cracks leading to intergranular creep fracture. Deformation twins and carbide precipitates were also observed. Oxidation tests were also carried out isothermally at $973 \mathrm{~K}$, $1023 \mathrm{~K}$, and $1073 \mathrm{~K}$ in dry air. The plots of mass gain versus square root time were linear at all the three test temperatures obeying parabolic kinetics of oxidation. It was found that scales are well adherent to the substrate. The plot of parabolic rate constant and inverse temperature was linear giving an activation energy value of $210 \mathrm{~kJ} / \mathrm{mol}$. The metallographic examination of an oxidized sample reveals duplex types of scales. Finally, rupture properties are compared with that of AISI 600 iron-based superalloy and oxidation weight gain analysis with surface nanocrystalline AISI 310 S stainless steel to analyze quantitatively its behavior.
\end{abstract}

\section{Introduction}

Materials operating at high temperature are subjected to creep, hot corrosion, erosion, and phase change which severely affect the temperature capability and load bearing capacity of materials [1]. AISI 310S stainless steel contains higher chromium and nickel content than common ironbased alloys [2-4]. It is a standardized high-temperature steel for use at temperatures of up to $1323 \mathrm{~K}$ in dry air. It has a unique combination of high strength and superior oxidation resistance for application up to $1323 \mathrm{~K}$. It is also very ductile and has good weldability enabling its widespread usage in many applications. It finds wide application in all high-temperature environments where scaling and corrosion resistance, as well as high temperature strength and good creep resistance, are required. Because of its superalloy properties, this alloy is a likely candidate material for hightemperature applications. It is a nonmagnetic alloy that cannot be hardened by heat treatment. It has forming capabilities similar to that of AISI 304 stainless steel. It can be easily formed into most shapes [5]. Extended capabilities of this stainless steel, beyond that of conventional stainless steels, make it potentially viable to replace nickel-based super alloys. A quantum of information connected with processing, tensile properties, oxidation, and hot corrosion properties of this alloy is available in the literature. The current research project focuses on the creep and hot corrosion of sheet samples taken from production run of Indian public sector stainless steel giant SAIL [5]. AISI 310S stainless steel flat rolled coil is primarily used for high-temperature situations. So, the alloy in the form of $1 \mathrm{~mm}$ thick sheets was used in the tests. Further, a comparison of creep data of this alloy with those of 
an iron-based superalloy AISI 600 is presented, as it is also a candidate material for jet engines and steam turbines $[6,7]$. Similarly, a comparison of oxidation data is made with surface nanocrystalline AISI 310 S stainless steel $[8,9]$.

\section{Experimental}

The materials investigated in creep rupture have the nominal composition of AISI 310 S stainless steel. The alloy was cut into $10 \mathrm{~cm} \times 10 \mathrm{~cm} \times 1 \mathrm{~mm}$. The sheets were solutionised at $1323 \mathrm{~K}$ for 2 hours in the furnace of Mayes creep testing machine and quenched in water. Soaking time is sufficiently high to ensure uniformity of temperature. It is 12 times higher than that required for mild steel sample of same thickness. This treatment ensures that all carbides are in solution. The composition was obtained using spectrometer. The specimens were longitudinally midsectioned, polished by conventional polishing techniques, and etched. The etched specimens were examined by optical microscopy. Creep specimens $1 \mathrm{~cm}$ gauge width and $10 \mathrm{~cm}$ gauge length were machined from the heat-treated pieces that correspond to ASTM E8M subsize specifications. All creep specimens were produced out of the centre of plates transverse to rolling direction. Creep tests were carried out in air at temperatures 973-1073 K in stress range $60-100 \mathrm{MPa}$ in a Mayes constant load creep testing machine. Test temperature $(T)$ was controlled by means of three PtRh-Pt thermocouples and kept constant at $T \pm 1 \mathrm{~K}$ by means of three PID control units. For creep measurement, the specimens were equipped with a double-coil extensometer, and the creep behavior as specimen elongation was registered continuously. The resolution was about $0.001 \mathrm{~mm}(1: 1250)$. Loading took place in normal atmosphere (air) via lever arm (1:15) using weights. The sample was allowed to soak at test temperature for 1 hour before the test load was applied. A number of different tests have been performed with standard specimens in the usual stress range $(60-100 \mathrm{MPa})$ at temperatures $973-1073 \mathrm{~K}$.

For oxidation kinetics, specimens with dimensions of $10 \mathrm{~mm} \times 10 \mathrm{~mm} \times 1 \mathrm{~mm}$ were cut from the heat-treated sheets, ground to 600-grit surface finish, and finally cleaned in ethanol. Isothermal oxidation tests were carried out in dry air at 973,1023 , and $1073 \mathrm{~K}$. The specimens were exposed for $200 \mathrm{~h}$. All specimens were used in the same condition. During testing, the specimens were tied in stainless steel wire, hanged in Mayes creep test unit's furnace, and both top and bottom of the furnaces were closed using ceramic wool, oxidized at the mentioned temperatures, and removed from the furnace at regular time intervals for weight change measurements $[10,11]$. Electronic balance was used to measure weights accurately for 5 decimal points. After oxidation, microstructure of oxidized surfaces was investigated.

\section{Results and Discussion}

The chemical composition was obtained accurately using vacuum evaporation spectrometer of the alloys considered in the analysis (Table 1). Usual optical metallographic procedure was used to get microstructure which consists mainly grain

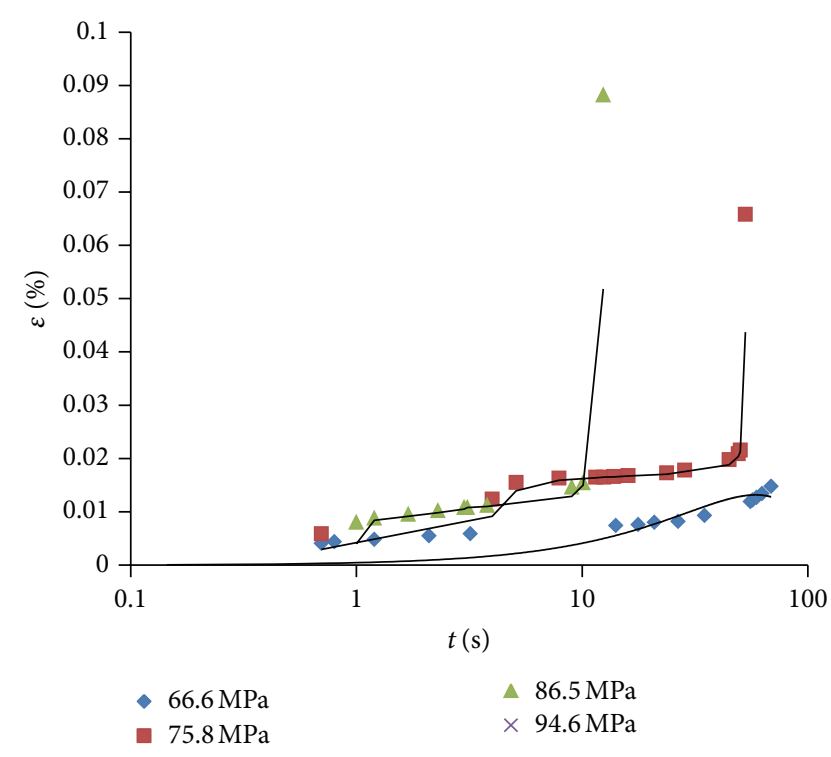

FIGURE 1: Creep curves of strain measured as a function of time for test temperature $1023 \mathrm{~K}$.

with a grain size of $100 \mu \mathrm{m}$. The microstructure consists of two phases, namely, gamma and carbide phases. Twins are also seen. It is very hard to see distinctly anything at carbides at low magnifications. But optical micrographs clearly reveal the presence of the carbides inside grains.

Present test temperatures $973-1073 \mathrm{~K}$ and stresses 60$100 \mathrm{MPa}$ fall in power-law creep (dislocation creep) region in deformation map. The region is governed by diffusioncontrolled climb-plus-glide processes such as (a) based on lattice diffusion-controlled climb (high-temperature creep), (b) based on core diffusion-controlled dislocation climb (lowtemperature creep), and (c) transition from climb-plus-glide to glide alone (power law breakdown). Typical creep curves at $973 \mathrm{~K}$ for loads of $66.6,74.8,86.6$, and $94.8 \mathrm{MPa}$ are shown in Figure 1. For the first three loads, all three regions of creep curves such as primary, secondary, and tertiary are available. Well-defined and longer secondary steady-state creep is noted well. But for the highest load, full strains are accumulated only during tertiary stage. Figure 2 shows typical creep curves for 86.5 MPa for temperatures 973, 1023, and $1073 \mathrm{~K}$. For the first two temperatures, all three regions of creep curves such as primary, secondary, and tertiary are available. Well-defined and longer secondary steady-state creep is noted well. But for the highest temperature, full strains are accumulated only during tertiary stage. Tests were conducted for all the three test temperatures and all the four loads. But for want of avoiding unnecessary discussion, other plots are not shown, and graphs available with full clarity are taken for presentation. The main factor which determines the shape of creep curve besides development of twins and dislocations is investigated here. The factor is creation, coalescence, and growth of creep cavities [6]. Figure 3 shows the stress dependence of steady-state creep rate for all the three temperatures. The data can be represented by a power law with a stress exponent of -6.5. An important 
TABLE 1: Chemical composition of AISI 310S stainless steel used in creep and oxidation studies along with surface-nanostructured AISI 310S stainless steel and heat-resistant AISI 600 iron-based superalloy taken for comparison.

\begin{tabular}{|c|c|c|c|c|c|c|c|c|c|c|c|}
\hline The alloys & $\mathrm{C}$ & $\mathrm{Mn}$ & $\mathrm{P}$ & $S$ & $\mathrm{Si}$ & $\mathrm{Cr}$ & $\mathrm{Ni}$ & Mo & $\mathrm{Ti}$ & $\mathrm{Al}$ & $\mathrm{V}$ \\
\hline Ordinary AISI 310S stainless steel & 0.08 & 1.25 & 0.045 & 0.030 & 0.96 & 24.8 & 18.5 & - & - & - & - \\
\hline $\begin{array}{l}\text { Surface nanocrystalline-structured } \\
\text { AISI } 310 \mathrm{~S}\end{array}$ & 0.04 & 0.97 & 0.016 & 0.001 & 0.61 & 25.0 & 19.5 & - & - & - & - \\
\hline AISI 600 iron-base-superalloy & 0.08 & 1.0 & 0.025 & 0.025 & 1.0 & 15.0 & 26.0 & 1.0 & 2.0 & 0.2 & 0.1 \\
\hline
\end{tabular}

significance of this observation is that the steady-state creep rate is controlled by the growth of the cavities nucleated at grain boundaries. Fractographic studies were not carried out, but optical metallographic images showed extensive voids. It is interesting to note that the dependence of steadystate creep rate on applied stress can be represented by a power law at all the three temperatures. Steady-state creep rate $\left(\dot{\varepsilon}_{s}\right)$ could be represented by the formula $\varepsilon_{s} \alpha \sigma^{-n} e^{-\mathrm{Q}_{c} / R T}$. Plots were also made to get activation energy. Logarithm of steady-state creep rate against inverse of temperature was used to get activation energy. Was obtained from the plot is $340 \mathrm{~kJ} / \mathrm{mol}$ and is a little higher than the self-diffusion value for gamma iron, that is, $300 \mathrm{~kJ} / \mathrm{mol}$. Figure 4 is the plot showing the effect of temperature on steady-state creep rate for stresses 75.8 and $86.5 \mathrm{MPa}$. Logarithm of steady state creep rate against inverse of temperature was used. Intercept of the plot is obtained, that is, the value of the constant $C$ in Larson-Miller parameter equation. One of the most popularly used techniques in representing creep-rupture data is Larson-Miller parameter. This parameter can be derived from the stress and temperature dependence of the creep rate or time to rupture. The rate equation generally can be written in the form of the Arrhenius equation and expressed as $P_{\mathrm{LM}}=T\left[C+\log \left(t_{r}\right)\right]$. The Larson-Miller model is used for experimental tests so that results at certain temperatures and stresses can predict rupture lives of time spans that would be impractical to reproduce in the laboratory (the plot of $\ln \sigma$ versus $P_{\mathrm{LM}}$ is a line (Figure 5)). To further compare the heat-resistant fully austenitic AISI 310S stainless steel with heat-resistant AISI 600 iron-based superalloy, the time to fracture is plotted against applied stress (Figure 6). Superalloy took the longest time to fail more than 3 times to that of the stainless steel. This indicates that solid solution strengthening, dispersion strengthening, and precipitation hardening are not significant compared to superalloy. The microstructures of crept samples compare well with typical of the literature data, and a typical micrograph is shown in Figure 7 [5].

The oxidation curves of weight gain per unit area versus time for all alloys after exposure at temperatures 973, 1023, and $1073 \mathrm{~K}$ are depicted in Figure 8. After $720 \mathrm{ks}$ exposure at all test temperatures, the alloy formed thicker oxide scales. Alloy showed the highest weight gain of $0.003 \mathrm{~kg} / \mathrm{m}^{2}$ at $1073 \mathrm{~K}$, followed by $1023 \mathrm{~K}$ with $0.002 \mathrm{~kg} / \mathrm{m}^{2}$, while for $973 \mathrm{~K}$, the weight gain was rather small which is below $0.001 \mathrm{~kg} / \mathrm{m}^{2}$. From the kinetics of oxidation at $973 \mathrm{~K}$, the corrosion behavior is similar to that of alloys with high chromium showing a protective oxidation, while the oxidation rate becomes

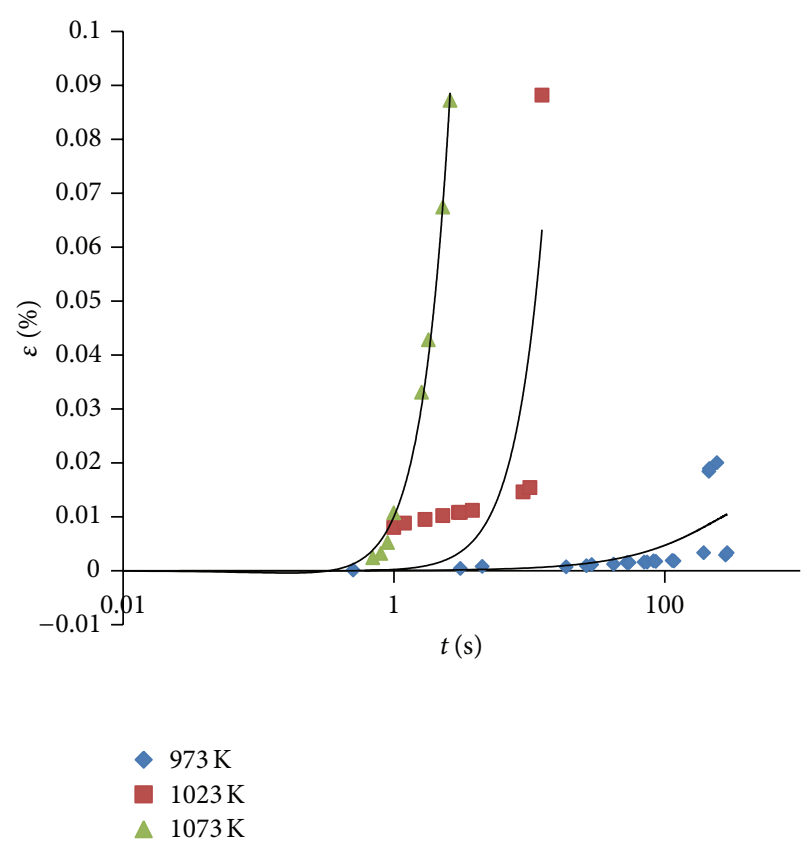

FIGURE 2: Creep curves of strain measured as a function of time for applied stress $86.5 \mathrm{MPa}$.

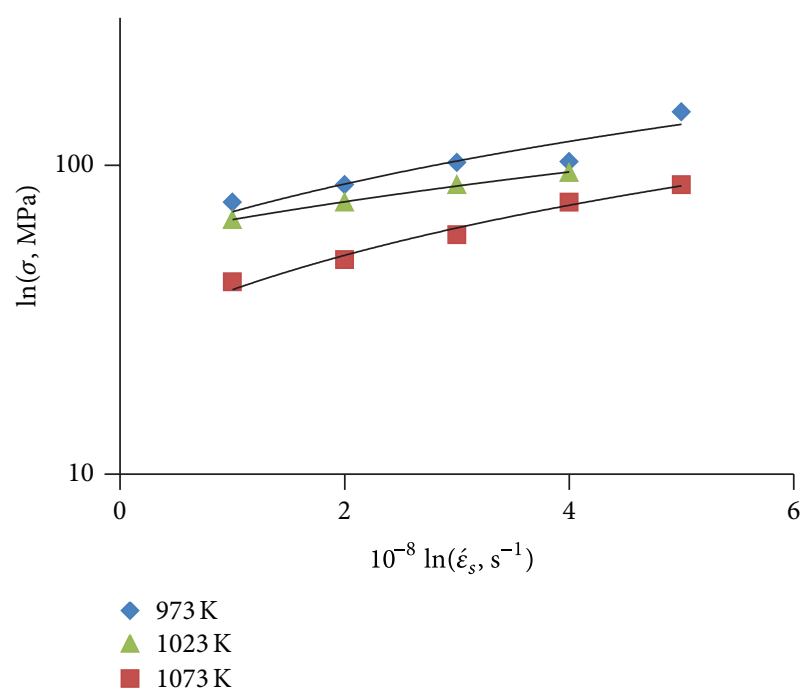

FIGURE 3: Effect of applied stress on steady-state creep rate at all test temperatures 973,1023 and $1073 \mathrm{~K}$. 


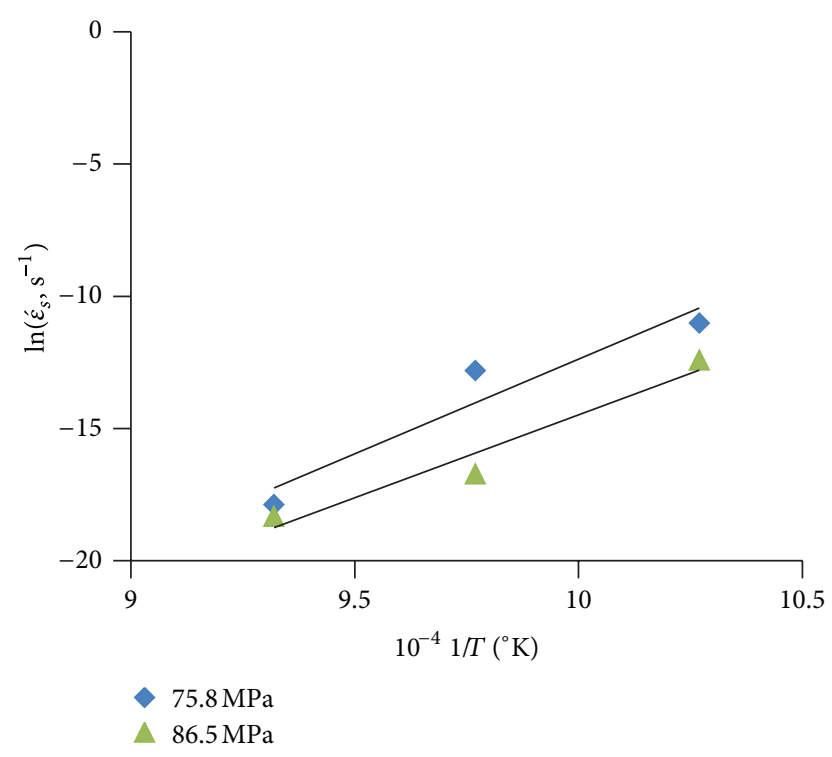

FIGURE 4: Effect of temperature on rupture life for stresses 75.8 and 86.5 MPa.

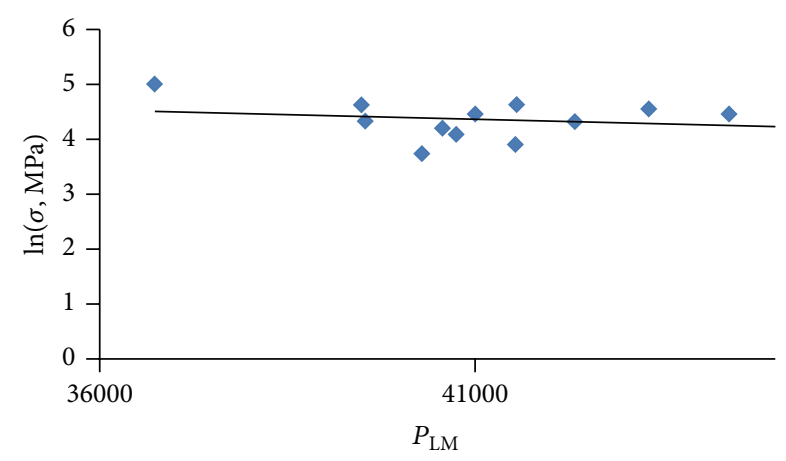

Figure 5: Master curve for temperatures 973-1073 K and stresses 66.6-94.6 MPa.

significantly larger at 1023 and $1073 \mathrm{~K}$. The average final weight gain of oxidation at $1073 \mathrm{~K}$ is higher than oxidation at $1023 \mathrm{~K}$ which in turn is higher than that at $973 \mathrm{~K}$ without any sudden phase change. The plot of square of weight gain per unit area versus time for all alloys after exposure at temperatures 973,1023 , and $1073 \mathrm{~K}$ is linear, and so it is inferred that the oxidation kinetics under this test condition follows parabolic growth law $\left(\Delta w^{2} \propto t e^{-Q_{c} / R T}\right)$. The slope provides oxidation rate constant. The rate constant is plotted versus inverse temperature to get activation energy. also $Q_{o}=$ $210 \mathrm{~kJ} / \mathrm{mol}$ (Figure 9). The cross-sectional analysis of the samples provides supporting evidence to this phenomenon. In terms of weight gain, similar trend of oxidation of that at all temperatures was observed. The slowest oxidation rate is in the alloy at $973 \mathrm{~K}$ showing protective behavior. Inspection of the surface of the oxide scales covering the specimens after the isothermal exposure for $720 \mathrm{ks}$ revealed that the part of the oxide grown spalled off (Figure 10). The finding is that at all temperatures $(973 \mathrm{~K}, 1023 \mathrm{~K}$ and $1073 \mathrm{~K}$ ), oxide layer

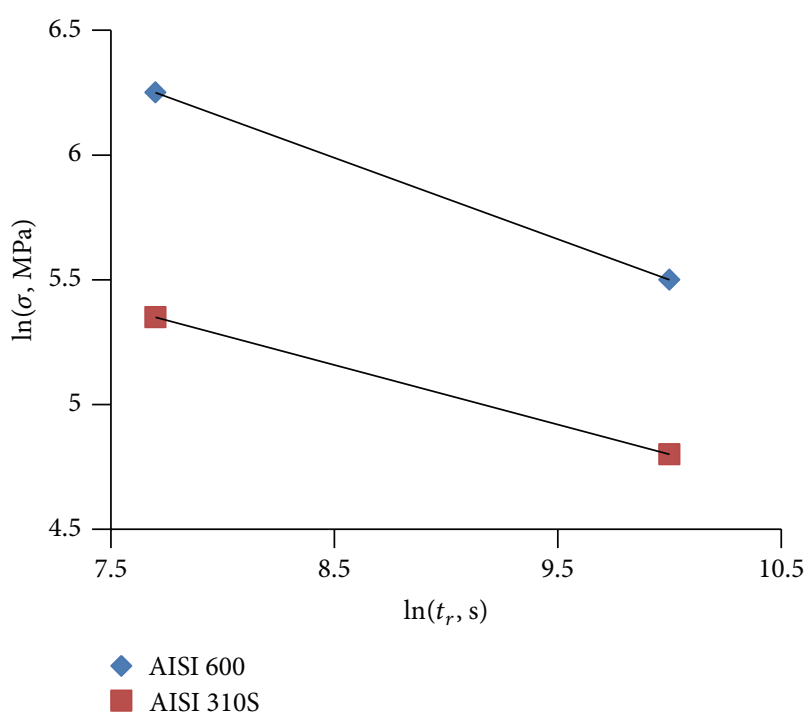

FIGURE 6: Effect of applied stress on rupture life at test temperature $923 \mathrm{~K}$ (AISI 600 compared).

showed considerable influence against further oxidation. Contrary to oxidation at lower temperature, exposure at $1073 \mathrm{~K}$ shows remarkable findings for the alloys. Even though the final weight gain for these alloys was relatively higher compared to exposure at the lower temperatures, they exhibit a parabolic behavior only even after $720 \mathrm{ks}$ exposure. The parabolic nature of the oxidation kinetics demonstrates that the initial oxidation is due to diffusion of the metal cation to the surface forming oxide films. Consequently, the oxidation proceeds by diffusion of oxygen through the initial layers towards the metal. From the experimental results, it is found that the main oxidation products are $\mathrm{Fe}_{2} \mathrm{O}_{3}$ and a mixture of $\mathrm{Fe}_{2} \mathrm{O}_{3}$ and spinel, whereby $\mathrm{Fe}_{3} \mathrm{O}_{4}$ is detected as the outermost oxide layer. This is because the $\mathrm{Fe}_{3} \mathrm{O}_{4}$ kinetics is typically greater than $\mathrm{Fe}_{2} \mathrm{O}_{3}$. The presence of $\mathrm{Cr}$ as a ternary element in the bulk alloy at $1073 \mathrm{~K}$ might reduce the outward diffusion of $\mathrm{Fe}$ and thus slow down the oxidation process. In addition, the addition of $\mathrm{Cr}$ may be incorporated with the oxidation reaction of the base alloy and result in modification of the structure of the oxides scale. These oxidation data are proved by microscopic examination of oxidized samples. Also, the oxidation behavior of it in normal condition and surface-modified condition provides interesting outcome. In oxidation studies, it is oxidized isothermally at $973 \mathrm{~K}, 1023 \mathrm{~K}$, and $1073 \mathrm{~K}$ in dry air. Previous researchers have indicated that addition of surface nanostructure has a beneficial effect on the oxidation resistance. Therefore, attention is also paid to review the effect of nanostructured surface as a comparison from the literature data in this study [8]. It is clear that the nanostructured surface is $30 \%$ better in oxidation weight change and $100 \%$ better in spalling resistance.

\section{Conclusions}

Creep rupture followed power law with stress exponent of 6.5. The activation energy for creep $(340 \mathrm{~kJ} / \mathrm{mol})$ was found 


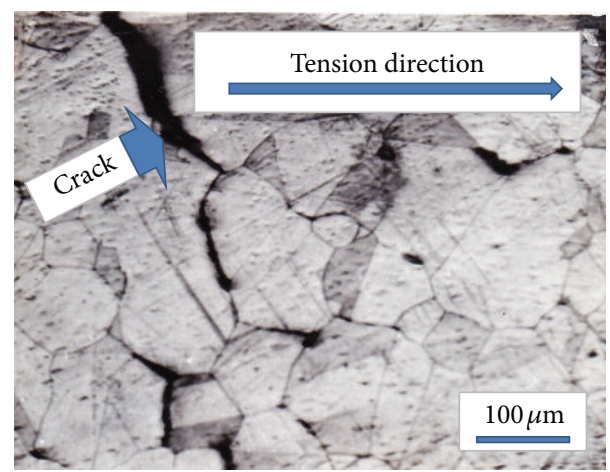

Figure 7: Optical micrograph of creep-ruptured sample at test temperature $1073 \mathrm{~K}$ and applied stress $66.6 \mathrm{MPa}$.

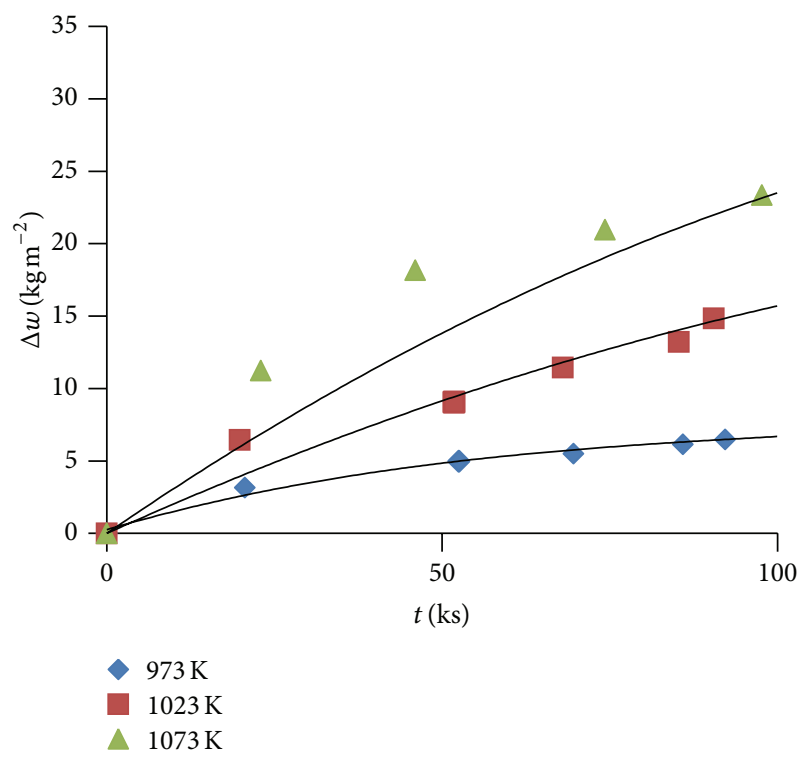

Figure 8: Plot of weight gain per unit area versus time for test temperatures 973,1023 , and $1073 \mathrm{~K}$.

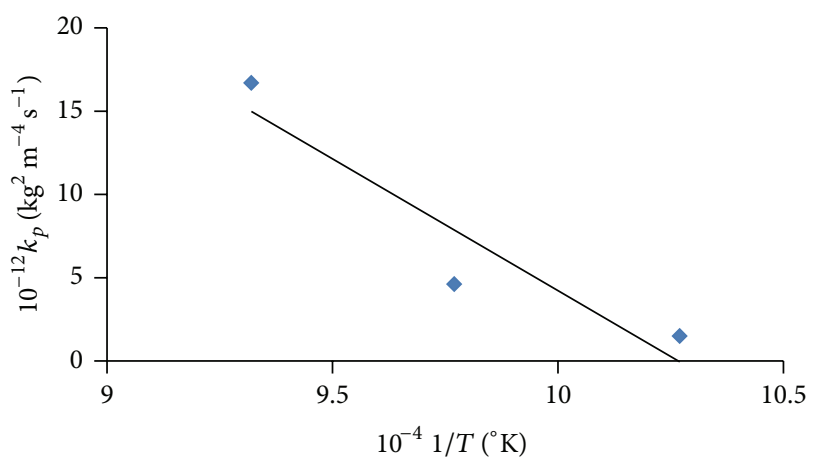

FIGURE 9: Plot of oxidation rate constant versus inverse of temperature. The activation energy from the plot is $210 \mathrm{~kJ} / \mathrm{mol}$.

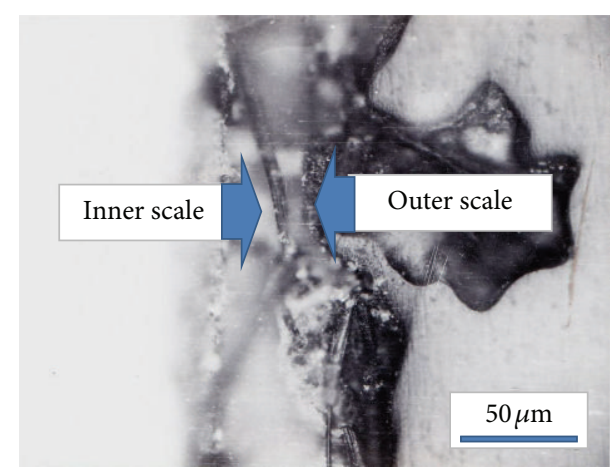

FIGURE 10: Optical micrograph of oxidized sample, taken in crosssection at $1023 \mathrm{~K}$ after $720 \mathrm{ks}$.

to be $10 \%$ higher than for lattice self-diffusion of $\gamma$-iron $(300 \mathrm{~kJ} / \mathrm{mol})$. The stress dependence of steady-state creep rate $\left(\hat{\varepsilon}_{s}\right)$ could be represented by a power law of form $\dot{\varepsilon}_{s} \alpha \sigma^{-n} e^{-Q_{c} / R T}$ (with $n=6.5$ and $Q_{c}=340 \mathrm{~kJ} / \mathrm{mol}$ ), for all the threes test temperatures. On comparison, rupture life of AISI 600 superalloy was found as 3 times better. Micrograph showed clearly the intergranular creep fracture. The crack runs perpendicular to load axis. Oxidation follows a parabolic kinetics, $\Delta w^{2} \alpha t e^{-Q_{o} / R T}$ (with $Q_{o}=210 \mathrm{~kJ} / \mathrm{mol}$ ), revealing the formation of protective oxide scale. Oxidized samples reveal an adherent inner layer and a spalling outer layer.

\section{Acknowledgment}

The project work was supported by GATE scholarship contingency grant of the National Institute of Technology, Tiruchirappalli, Tamil Nadu, India.

\section{References}

[1] M. E. Kassner and M. T. Perez Prado, "Five-power-law creep in single phase metals and alloys," Progress in Materials Science, vol. 45, no. 1, pp. 1-102, 2000.

[2] A. Kanni Raj, Creep: Basic Theory and Dissertation, AV, Saarbrücken, Germany, 2011.

[3] K. Maruyama, H. Ghassemi Armaki, and K. Yoshimi, "Multiregion analysis of creep rupture data of 316 stainless steel," International Journal of Pressure Vessels and Piping, vol. 84, no. 3, pp. 171-176, 2007.

[4] R. Voicu, J. Lacaze, E. Andrieu, D. Poquillon, and J. Furtado, "Creep and tensile behaviour of austenitic Fe-Cr-Ni stainless steels," Materials Science and Engineering A, vol. 510-511, pp. 185-189, 2009.

[5] S. S. M. Tavares, V. Moura, V. C. da Costa, M. L. R. Ferreira, and J. M. Pardal, "Microstructural changes and corrosion resistance of AISI $310 \mathrm{~S}$ steel exposed to $600-800{ }^{\circ} \mathrm{C}$," Materials Characterization, vol. 60, no. 6, pp. 573-578, 2009.

[6] S. Srinivas, D. V. V. Satyanarayana, and M. C. Pandey, "Creep testing," Transactions of the Indian Institute of Metals, vol. 49, pp. 625-640, 1996.

[7] H. De Cicco, M. I. Luppo, H. Raffaeli, J. Di Gaetano, L. M. Gribaudo, and J. Ovejero-García, "Creep behavior of an A286 
type stainless steel," Materials Characterization, vol. 55, no. 2, pp. 97-105, 2005.

[8] Z. Liu, Y. He, and W. Gao, "Surface nanocrystallization of 310s stainless steel and its effect on oxidation behavior," Journal of Materials Engineering and Performance, vol. 7, no. 1, pp. 88-92, 1998.

[9] M. L. Lau and E. J. Lavernia, "Microstructural evolution and oxidation behavior of nanocrystalline 316-stainless steel coatings produced by high-velocity oxygen fuel spraying," Materials Science and Engineering A, vol. 272, no. 1, pp. 222-229, 1999.

[10] A. M. Huntz, A. Reckmann, C. Haut et al., "Oxidation of AISI 304 and AISI 439 stainless steels," Materials Science and Engineering A, vol. 447, pp. 266-276, 2007.

[11] A. Kanni Raj, "Creep and hot corrosion behavior of fully austenitic heat resistant SAIL's AISI 310S stainless steel," in Proceedings of the 6th International Conference on Creep, Fatigue and Creep-Fatigue Interaction, Kalpakkam, India, 2012. 

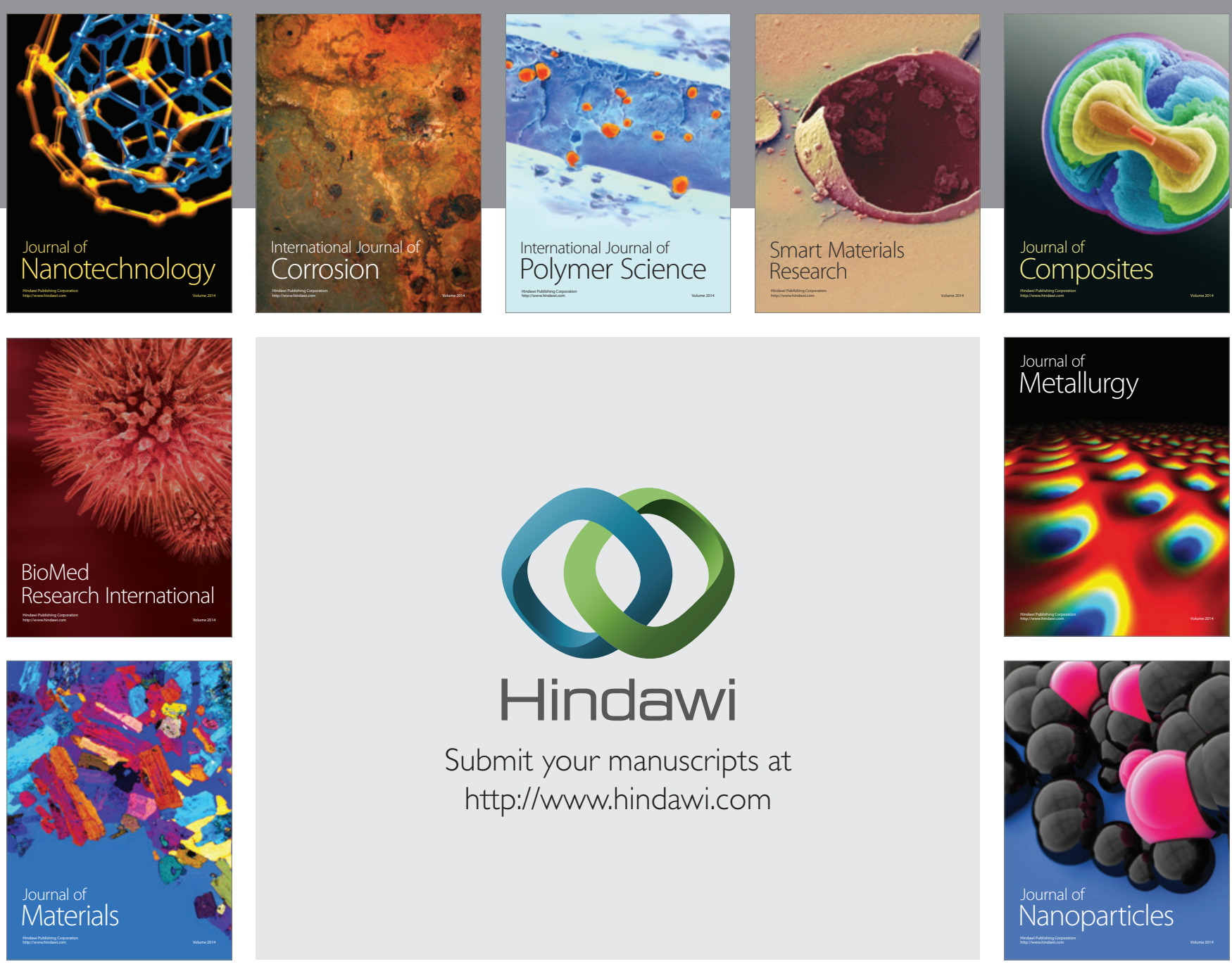

Submit your manuscripts at http://www.hindawi.com
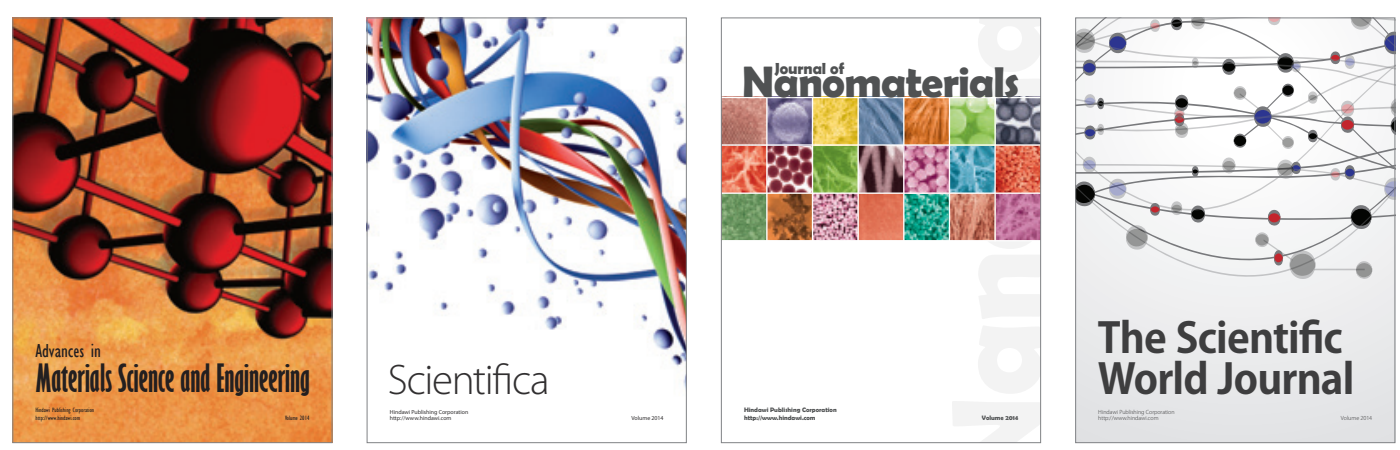

\section{The Scientific World Journal}
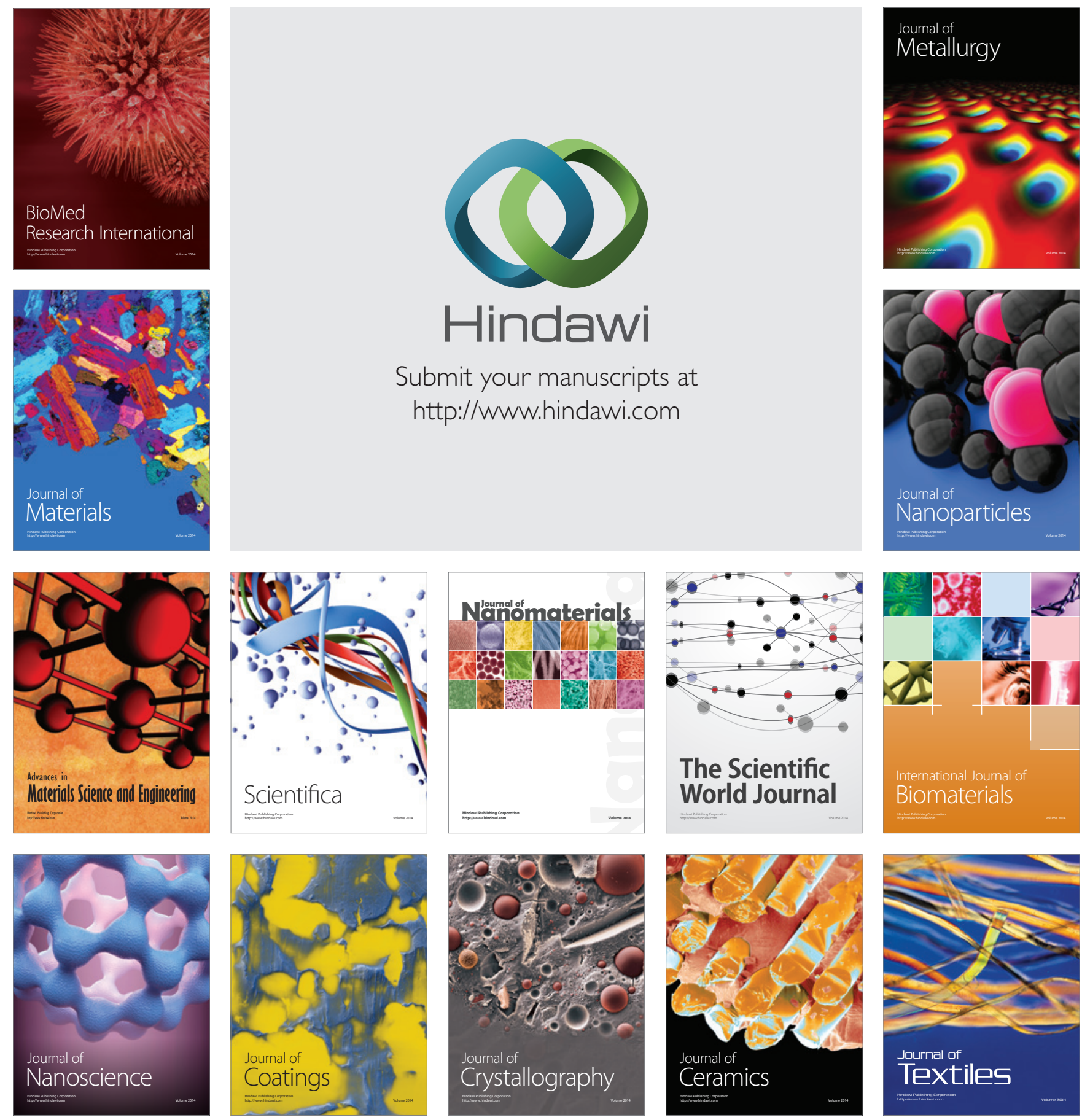